Eos, Vol. 85, No. 28, 13 July 2004

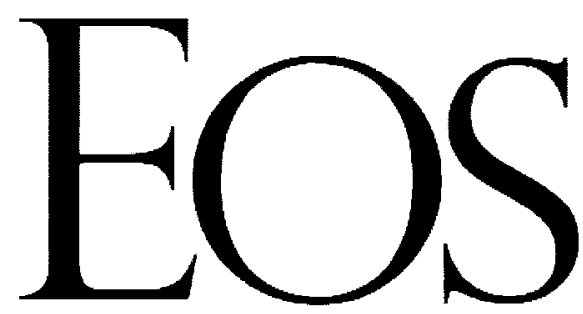

VOLUME 85 NUMBER 28

13 JULY 2004

\title{
Proposed Initiative Would Study Earth's Weathering Engine
}

\section{PAGES 265, 269}

At the Earth's surface, a complex suite of chemical, biological, and physical processes combines to create the engine that transforms bedrock into soil (Figure 1). Earth's weathering engine provides nutrients to nourish ecosystems and human society, mediates the transport of toxic components within the biosphere, creates water flow paths that carve and weaken bedrock, and contributes to the evolution of landscapes at all temporal and spatial scales. At the longest time scales, the weathering engine sequesters $\mathrm{CO}_{2}$, thereby influencing long-term climate change.

Despite the importance of soil, our knowledge of the rate of soil formation is limited because the weathering zone forms a complex, ever-changing interface, and because scientific approaches and funding paradigms have not promoted integrated research agendas to investigate such complex interactions. No national initiative has promoted a systems approach to investigation of weathering science across the broad array of geology, soil science, ecology, and hydrology. Such a program is certainly needed, and this article describes a platform on which to build the initiative to answer the following question: How does the Earth weathering engine break down rock to nourish ecosystems, carve errestrial landscapes, and control carbon dioxide in the global atmosphere?

Only with such an effort will it be possible to predict how weathering rates in the "Critical Zone" [National Research Council Committee on Basic Research Opportunities in the Earth Sciences, 2001] (Figure 2) respond to climatic, tectonic, and anthropogenic forcings over all temporal and spatial scales. Such an initiative is proposed, described at present as the Weathering System Science Consortium (WSSC). Input for its future development is sought from the geosciences community (http://www.wssc. psu.edu/).

By SuzAnne P.Anderson, Joel Blum, Susan L. Brantley, Oliver Chadwick, Jon Chorover, Louis A. DeRry, James I. DREVER, JANET G. HeRING, James W. KIRCHNER, LEE R. KUMP, DANIEL RICHTER, AND ART F. White

\section{What is WSSC?}

Research that addresses the complex response of weathering to climatic, tectonic, and anthropogenic forcings (Figure 1) is presently conducted by a diverse group of disciplinary scientists, including geochemists, geomorphologists, soil scientists, and ecologists. Without targeted funding to understand the feedbacks controlling weathering as a system, individual research efforts lack the comprehensiveness and depth needed to develop a process-level understanding of weathering. In contrast, development of a concerted programmatic initiative will promote a systems approach to investigations of weathering, by promoting interactions among different disciplines; standardizing data and sample collection for weathering systems; decoupling complex biophysico-chemical systems with quantitative models; providing data bases and sample storage facilities for weathering profiles; providing expertise in field-based data collection; and training a new cohort of weathering specialists; and integrating field-based, computational, and experimental approaches.

The idea of WSSC has been developed with support from the U.S. National Science Foundation by scientists seeking to build support for a national initiative. The current model for WSSC is to develop an interdisciplinary program to promote the systems approach to weathering science to identify forcings and feedbacks at all scales (Figures 1 and 2).

The current plan for WSSC incorporates four basic components. First, a set of three "node" sites is envisioned. These will be highly instrumented, hierarchically nested field sites designed to investigate weathering at the soil profile and catchment scales. Such sites will be chosen by peer review from new or previously investigated sites.

Second, a network is envisioned of "backbone" soil sites that will be measured for a standard set of weathering parameters over a range of depths. Parameters to be measured will include mineralogy, chemistry, concentration of soil organic matter, exposure age, and mineral surface area, among other attributes. By standardizing data and sample collection for these backbone sites, WSSC will promote inter-comparison of weathering across a variety of lithologies, ecosystems, and topographies. A large number of backbone sites will be investigated.

Third, to enable intercomparison of weathering data, WSSC will provide technical support to instrument or sample node sites and backbone sites similarly, and will provide coordinated data management and sample storage systems. Data and samples will be accessible to all scientists, allowing new and emerging methodologies to be tested on well-characterized samples as projects unfold.

Fourth, and perhaps most important, WSSC will promote the integration of these efforts through a variety of community-building approaches. For example, WSSC fellowships will be provided to researchers who will integrate data from node and backbone sites through the implementation of quantitative weathering models. Yearly WSSC meetings and workshops will promote advances and will introduce models to interpret weathering systems.

\section{Driving Questions}

The question posed about Earth's weathering engine is a first-order query in the Earth sciences; one that cannot be quantitatively answered at this time. We can place bounds on this broad question by asking specific questions. First, how can the dominant factors controlling chemical weathering be identified and their effects be quantified in a given environment and at various scales?

Mineral surface structure and chemistry, solution chemistry, exposure age, and the physical properties of rock all affect weathering rates (for example, see Figure 3 ). These effects can be studied in isolation through controlled laboratory experiments. However, in soil profiles, hydrologic issues emerge, including structure of porosity, reactive surface area, and permeability (for example, see Figure 1). Over entire landscapes, rates of regolith production and physical transport determine the exposure age and the regolith thickness (for example, see Figure 2). Plant and microbial communities affect rock weathering through fixation and transformation of solar energy, hydrological impacts, production of acidity, and cycling of organic carbon. The effect of all of these variables, including slope, climate, hydrology, lithology, structural properties, tectonics, anthropogenic factors, and biota must be quantified with respect to the weathering profile, the weathering rate, and the rate of 
Eos, Vol. 85, No. 28, 13 July 2004

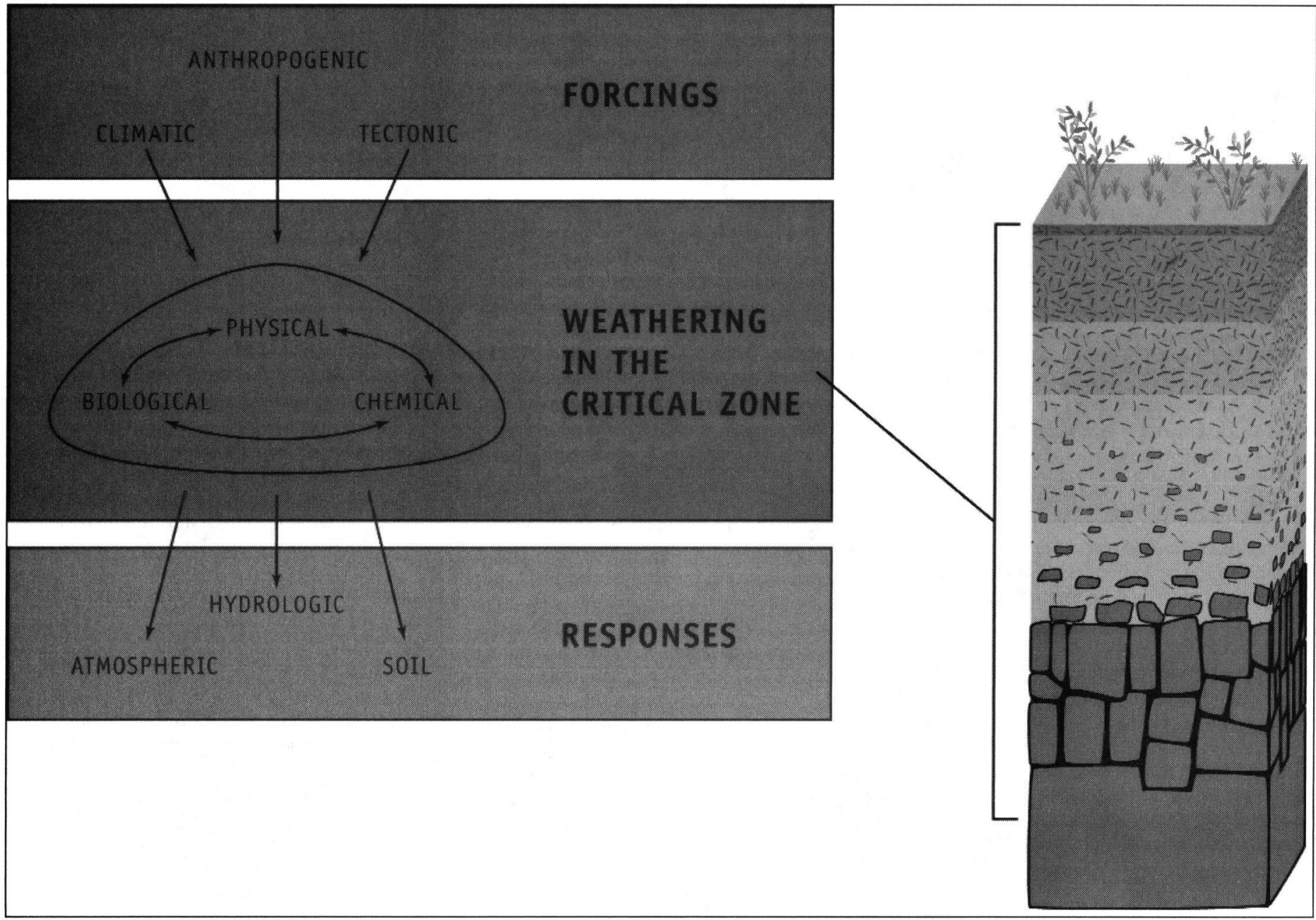

Fig. 1.The coupled chemical, physical, and biological processes that define the Earth's weathering engine are driven by climatic, anthropogenic, and tectonic forcings that can be investigated at the hand specimen and soil profile scale. The characteristic rates and extents of weathering are recorded in the concentrations of atmospheric gases, in hydrologic responses, and in soil chemistry, and can be inferred from historical data and from the geologic record. Original color image appears at back of this volume.

denudation [Berner and Berner, 1997;

Birkeland, 1999].

The second question is, in what ways are physical, chemical, and biological weathering processes coupled, and how can these couplings be elucidated and quantified?

One of the most exciting challenges for WSSC is derived from the coupled nature of physical, chemical, and biological weathering processes in the weathering zone (Figure 1) [Hotchkiss et al., 2000]. These coupled processes create a system that regulates the rates of soil formation and the composition and physical characteristics of the soil through a web of feedback loops. Chemical weathering can increase permeability, which enhances the influx of water, and in turn increases the water-mineral interfacial area and dissolution rate. Tectonic activity affects relief and erosion, and hence, the thickness of the weathering profile, which controls the reactivity of the soil solutions at the bedrock-saprolite interface.

Similarly, organisms growing within soils serve to both enhance or suppress weathering rates. In transport-limited regimes [White and Brantley, 1995], biological cycling of nutrients becomes decoupled from rock weathering, whereas in weathering-limited regimes where erosion keeps rock near the surface, a tight coupling between weathering and biological cycling is observed. We need to quantify how biological processes are controlled or isolated from the depth-advance rate of the bedrock-saprolite interface over $10^{3}$ to $10^{5}$-year time scales using isotopic and elemental tracers, enhanced environmental sensors, better imaging methods, and more powerful models [Chadwick et al., 1999].

The third question is, how can we advance our ability to predict weathering processes over the range of pertinent spatial scales, including mineral surfaces, laboratory reactors, soil profiles, catchments, and global systems?

Central to WSSC is the need to extrapolate information across spatial scales (Figure 2). For example, weathering rates measured in the laboratory exceed those in the field by up to five orders of magnitude [White and Brantley, 1995]. To extrapolate across scales, we must first establish where weathering is occurring in natural systems, and we often do not know the answer to this question (Figure 3). To integrate measured fluxes at each scale into coherent predictive models, we need to quantify the reactive interfacial area that dominates chemical fluxes. However, the form of scaling parameters will vary as we move from atoms and particles, to soil profiles, to catchments, to watersheds, because water does not sample all available surfaces equally. Thus, scaling parameters must couple reactive surface area to the spatial distribution of water fluxes. Incorporation of biological fluxes at all scales of analysis also provides a serious challenge.

The fourth question is, how do weathering processes change and evolve over human time scales and over geologic time, and what approaches are useful in predicting the temporal evolution of weathering products and elemental fluxes?

Weathering rates change over geologic time and are changing today due to anthropogenic impacts [Raymond and Cole, 2003]. In addition, weathering systems respond to perturbations over time scales ranging from minutes (response to rainstorms, equilibration of sorption processes) to millennia (development of residual soil profiles, response to climate change). The chemical signatures of the dissolved and suspended loads, as well as the residual minerals provide a tracer of the long-term stability of landscapes. Paleo-sols and ocean sediments preserve these tracers, allowing interpretation of paleo-environmental change. The use of 
Eos, Vol. 85, No. 28, 13 July 2004

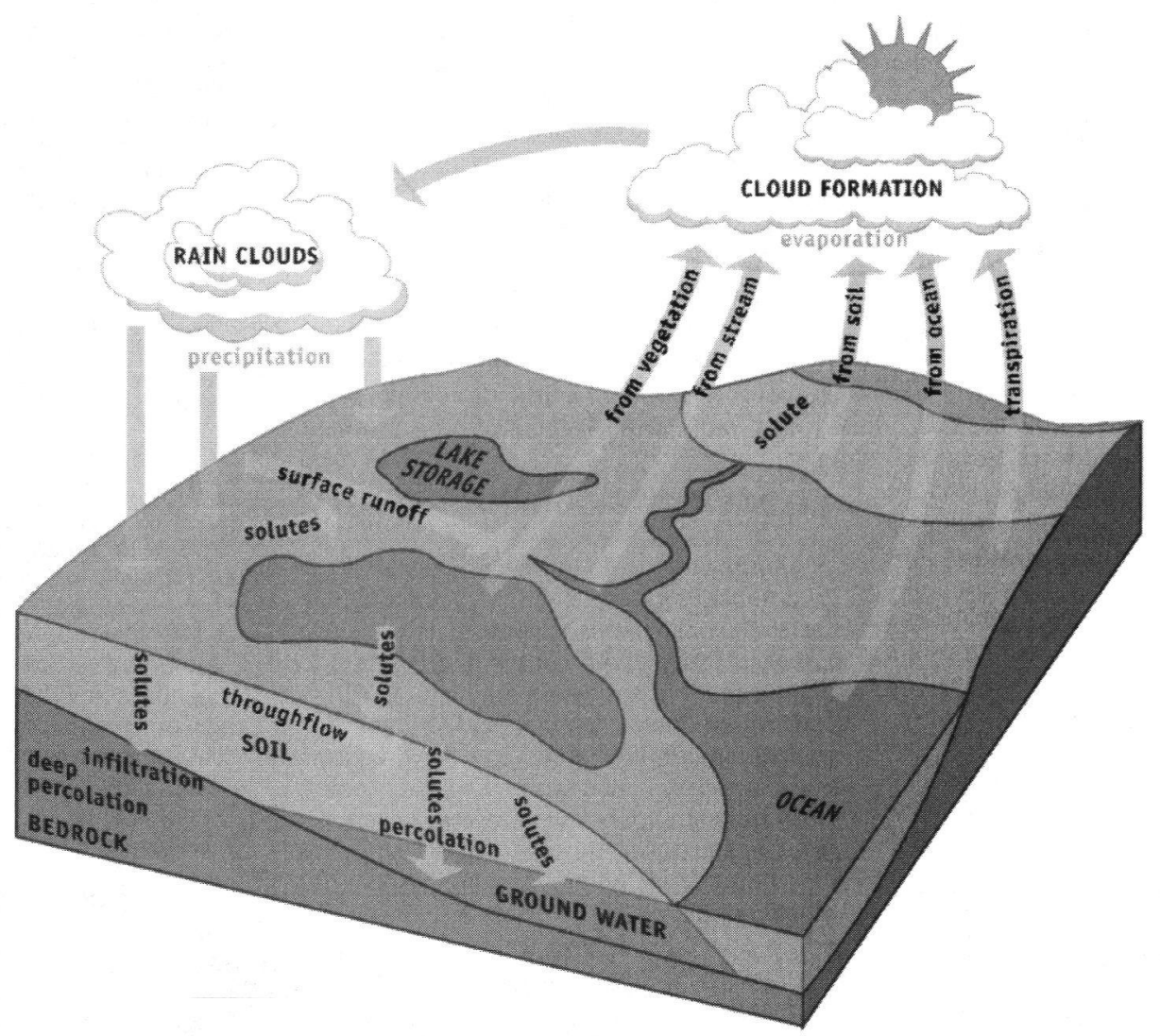

Fig. 2. Geochemical cycling of elements during weathering can be monitored through solute and water budgets measured at the watershed scale. Original color image appears at back of this volume.

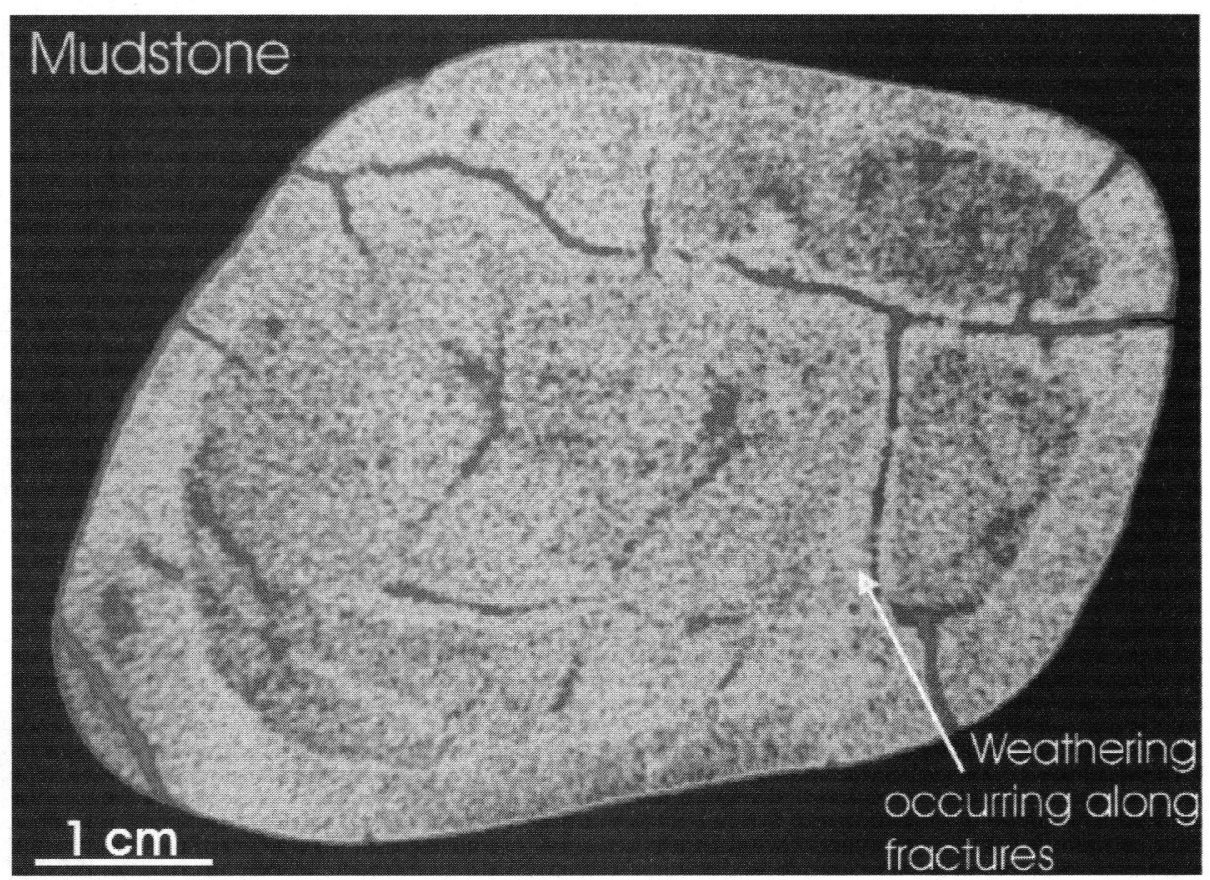

Fig. 3. New imaging techniques such as computer tomography (CT), shown here for a weathered mudstone clast from a soil developed over $120 \mathrm{ka}$ in Costa Rica, can identify where weathering occurs throughout a rock. CT uses $X$ rays to image low to high density (blue to red). (Imaged at the Center for Quantitative Imaging, Penn State University, by A. Navarre, A. Grader, and P. Halleck.) Original color image appears at back of this volume. 
chronosequences (soils of varying exposure age developed within the same climate on the same lithology) as natural laboratories also promises to document the effects of age on weathering over $10^{3}$ to $10^{6}$ years [White and Brantley, 1995].

\section{Societal Implications}

These fundamental questions are not isolated from societal issues. To address issues with respect to the atmosphere, we must understand the effect of $\mathrm{CO}_{2}$ concentration on carbon fluxes during weathering; and the impacts of soil mineralogy on carbon sequestration [Torn et al., 1997; Andrews and Schlesinger, 2001] must be investigated. As we begin to sequester carbon in geologic reservoirs, we must quantify rates of mineral weathering. Buffering of acid precipitation by reaction with minerals also links ecosystems to estimates of critical loads of acidity.

Furthermore, mineral weathering controls the quality of groundwater, a critical resource that provides approximately $50 \%$ of the U.S. domestic water supply. Such socially important weathering reactions span the weathering of natural rock components, such as arsenic, to the weathering of contaminant-containing phases introduced by humans. Weathering issues related to acid mine drainage have resulted in pollution of over 2400 miles of streams in Pennsylvania alone.

Finally, we now realize that almost half of the land surface on Earth has been transformed by human activity [Vitousek et al., 1997], including vast and sometimes deleterious transformations of soils. Understanding and predicting such global change is necessary as we seek to mitigate anthropogenic impacts on the Earth.

\section{What Advances Drive WSSC?}

The Weathering System Science is poised to move forward rapidly because of new developments in the field, in the laboratory, and in modeling. For example, cosmogenic isotopes are now used to estimate exposure ages for weathering landscapes. Availability of these ages has led to the integration of geochemical studies with cosmogenic estimates of denudation [e.g., Heismath et al., 1997]. Emerging spectroscopic tools, including synchrotron techniques, promise to interrogate the nano-scale character of weathering systems, yielding information that can be integrated into models of weathering at other scales. Newly available techniques for interpreting weathering rates in field systems using both water and soil chemistry are also now available and should be implemented extensively. The availability of a laboratory data set for mineral weathering [White and Brantley, 1995] has set the stage for modeling weathering across all these scales using reactive transport codes; models with sufficient power to incorporate fully coupled reaction and transport have only been available for investigation of complex weathering problems for the last several years. Furthermore, emerging technologies such as micro-electrodes and other environmental sensors may soon provide in situ chemical information for field systems. Time-domain reflectometry (TDR), remote sensing, and tomographic imaging techniques (for example, Figure 3) will facilitate the mapping of heterogeneities.

In addition, tools such as ground-penetrating radar, geographic information systems, and geospatial statistical techniques will contribute to the unraveling of the complexities of weathering systems.

Single-principal investigator investigations have advanced weathering science, but to achieve an integrated understanding, a new funding initiative to drive collaborative interdisciplinary science is needed. We propose such an initiative and look to weathering scientists from all disciplines for guidance and participation in the coming months. News of developments and upcoming meetings aimed at promoting an initiative in weathering system science are posted at the WSSC Web site: http://www.wssc.psu.edu/.

\section{Acknowledgments}

The following individuals also participated in the U.S. National Science Foundation-funded meeting to discuss WSSC and contributed to the ideas in this article: Ruth Blake, Sigurdur Gislason, Jerome Gaillardet, Claudia Mora, and Carl Steefel.

\section{References}

Andrews, J.A., and W. H. Schlesinger (2001), Soil $\mathrm{CO}_{2}$ dynamics, acidification, and chemical weathering in a temperate forest with experimental $\mathrm{CO}_{2}$ enrichment, Global Biogeochem. Cyc., 15, 149-162.

Berner, R.A., and E. K. Berner (1997), Silicate weathering and climate, in Tectonic Uplift and Climate Change, edited by W. F.Ruddiman, pp. 353-364, Plenum Press, New York.

Birkeland, PW. (1999), Soils and Geomorphology, 3rd. Ed., Oxford University Press, N.Y., 430 pp.

Chadwick, O. A., L. A. Derry, P.M. Vitousek, B. J. Huebert, and L. O. Hedin (1999), Changing sources of nutrients during four million years of ecosystem development, Nature, 397, 491-497.

Heimsath, A. M.,W.E. Dietrich, K. Nishiizumi, and R. C. Finkel (1997), The soil production function and landscape equilibrium, Nature, 388 (6640), 358-361.

Hotchkiss, S. C., P.M. Vitousek, O. A. Chadwick, and J. P. Price (2000), Climate cycles, geomorphological change, and the interpretation of soil and ecosystem development, Ecosystems, 3(6), 522-533.

National Research Council Committee on Basic Research Opportunities in the Earth Sciences (2001), Basic Research Opportunities in the Earth Sciences, National Academies Press, Washington, D.C. Raymond, P.A., and J.J.Cole (2003), Increase in the export of alkalinity from North America's largest river, Science, 301(5629), 88-91.

Tom, M. S., S.E. Trumbore, O.A. Chadwick, and D. M. Hendricks (1997), Mineral control of soil organic carbon storage and turnover, Nature, 389(6647), 170-173.

Vitousek, P.M., H. A. Mooney, J. Lubchenco, and J. M. Melillo (1997), Human domination of Earth's ecosystems, Science, 277(5325), 494-499.

White,A.F, and S. L. Brantley (eds.) (1995), Chemical Weathering Rates of Silicate Minerals, Mineralogical Society of America, Washington, D.C.

\section{Author Information}

Suzanne PAnderson, University of Colorado at Boulder; Joel Blum, University of Michigan, Ann Arbor; Susan L. Brantley, Penn State University, University Park; Oliver Chadwick, University of California, Santa Barbara; Jon Chorover, University of Arizona, Tucson; Louis A. Derry, Cornell University, Ithaca, N.Y.; James I. Drever, University of Wyoming, Laramie; Janet G. Hering, California Institute of Technology, Pasadena; James W. Kirchner, University of California, Berkeley; Lee R. Kump, Penn State University, University Park; Daniel Richter, Duke University, N. C.; and Art FWhite, U.S. Geological Survey, Menlo Park, Calif.

For additional information, contact Susan L. Brantley, Earth and Environmental Systems Institute, 2217 Earth and Engineering Building, Penn State University, University Park, PA 16802; E-mail: brantley@essc. psu.edu. 
Eos, Vol. 85, No. 28, 13 July 2004

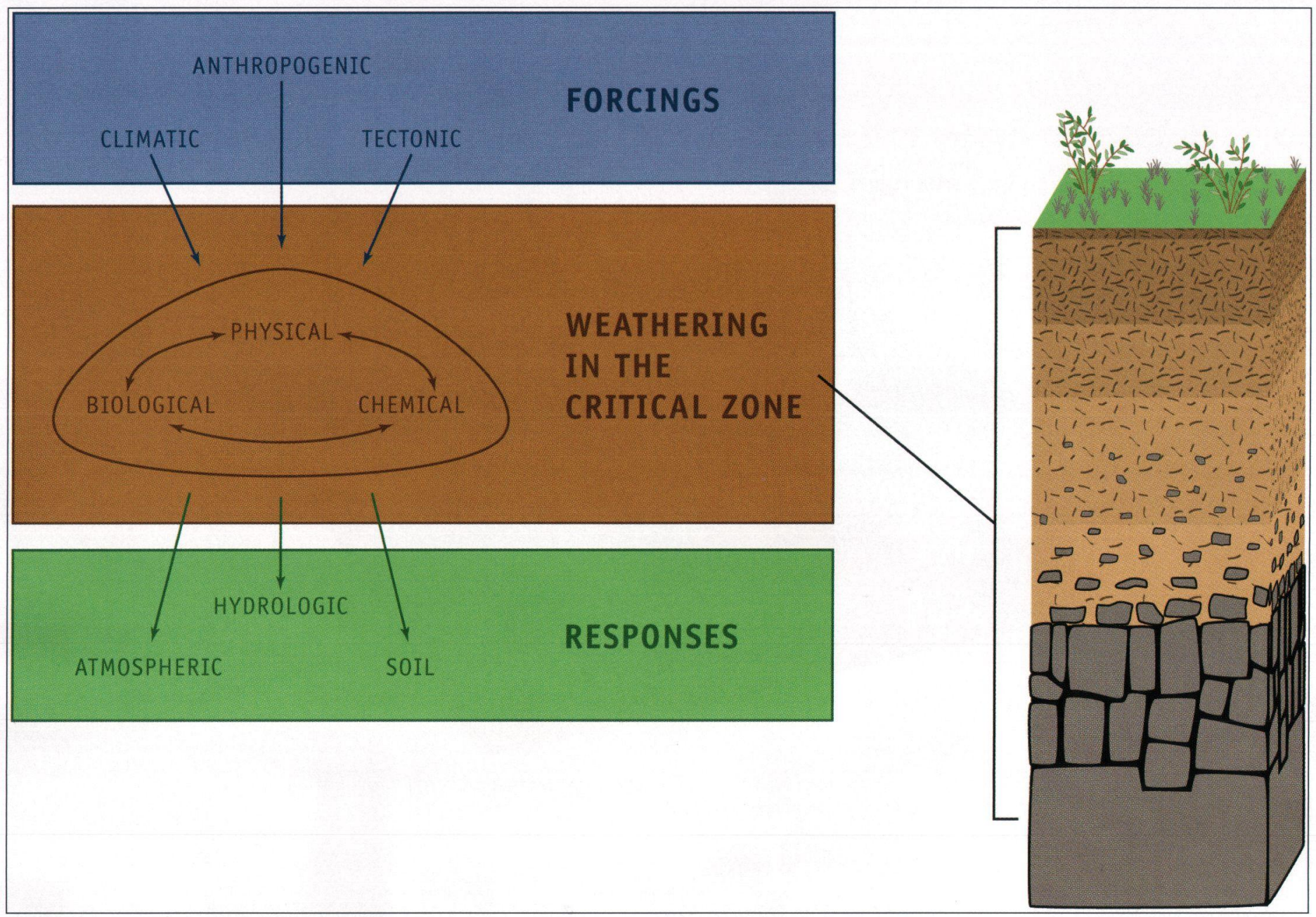

Fig. 1. The coupled chemical, physical, and biological processes that define the Earth's weathering engine are driven by climatic, anthropogenic, and tectonic forcings that can be investigated at the hand specimen and soil profile scale. The characteristic rates and extents of weathering are recorded in the concentrations of atmospheric gases, in hydrologic responses, and in soil chemistry, and can be inferred from historical data and from the geologic record. 
Eos, Vol. 85, No. 28, 13 July 2004

Page 269

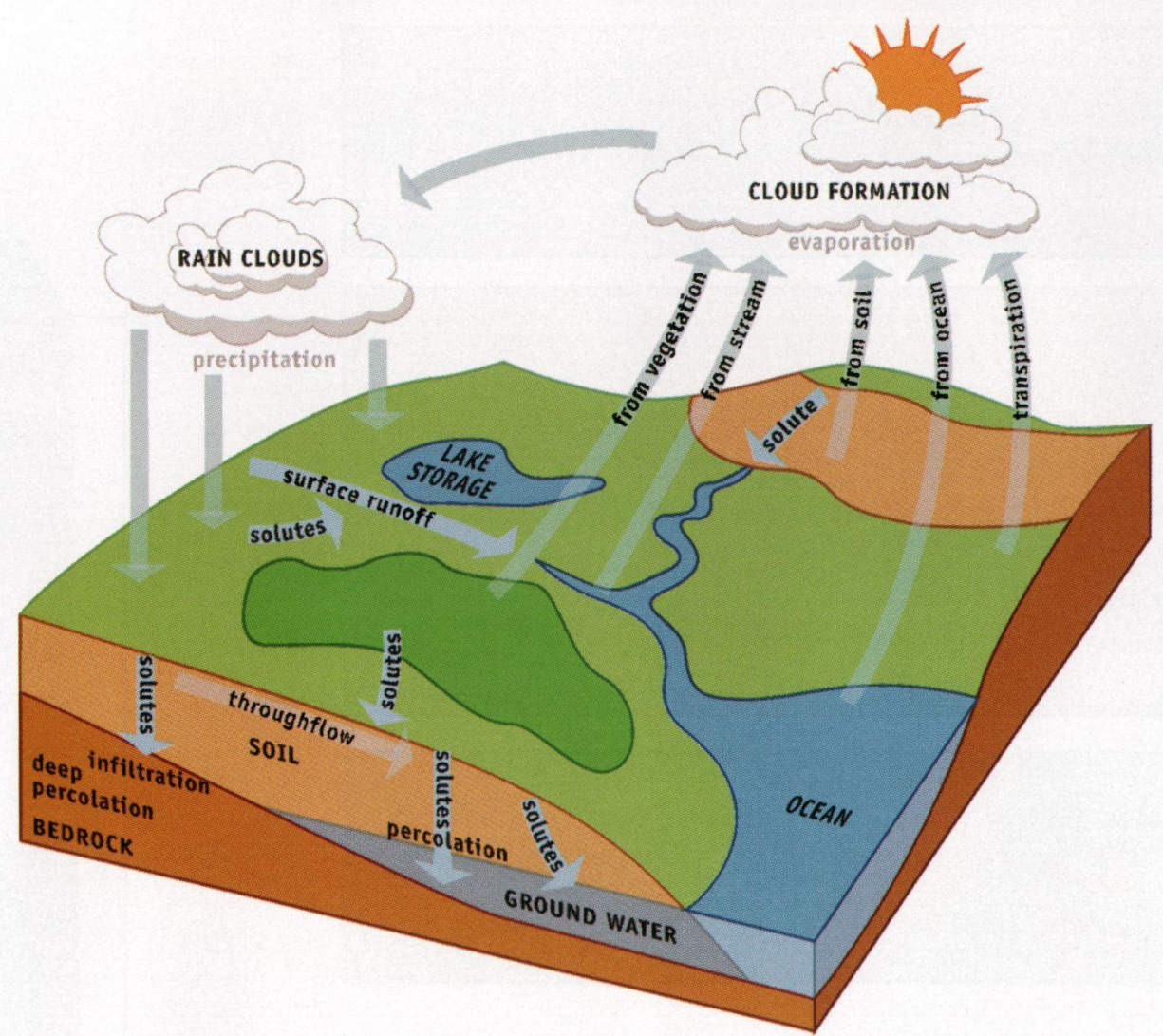

Fig. 2. Geochemical cycling of elements during weathering can be monitored through solute and water budgets measured at the watershed scale.

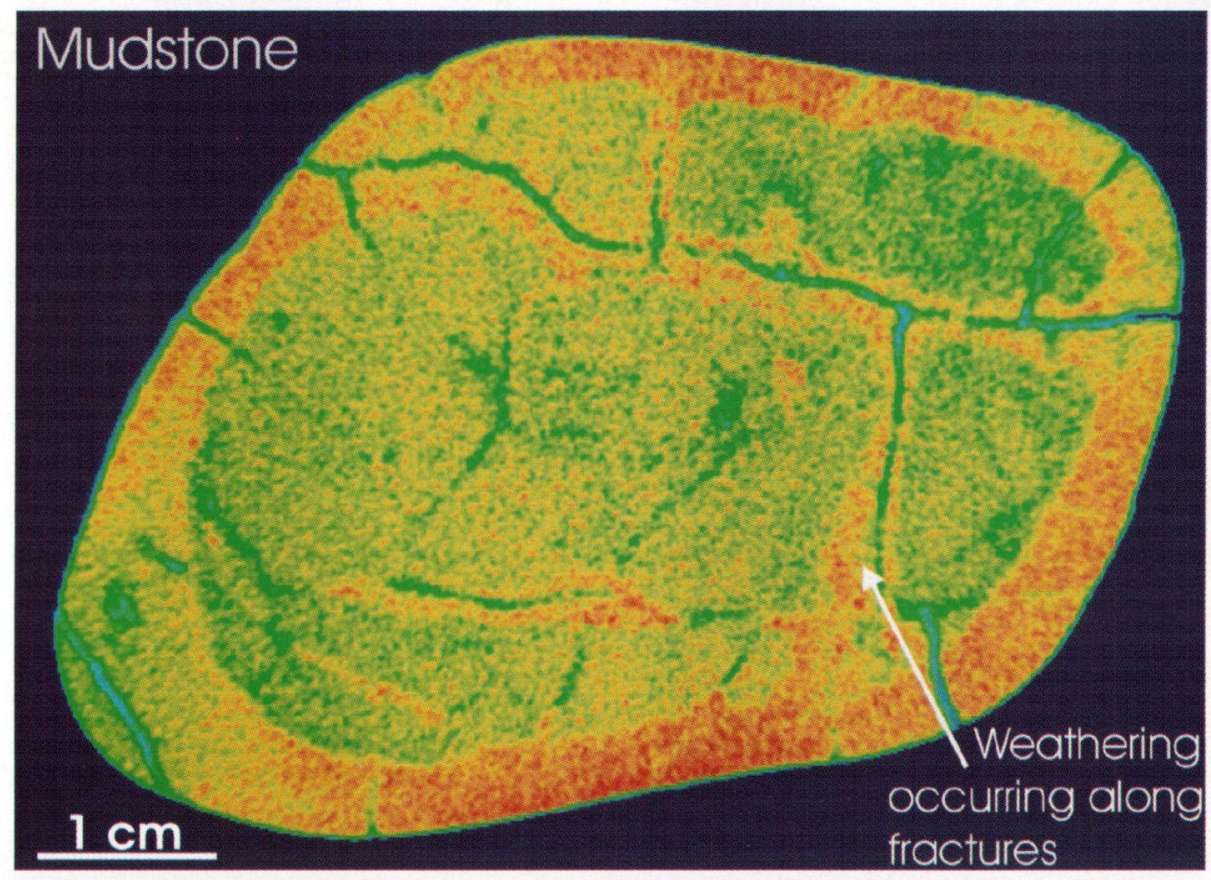

Fig. 3. New imaging techniques such as computer tomography (CT), shown here for a weathered mudstone clast from a soil developed over $120 \mathrm{ka}$ in Costa Rica, can identify where weathering occurs throughout a rock. CT uses X rays to image low to high density (blue to red). (Imaged at the Center for Quantitative Imaging, Penn State University, by A. Navarre, A. Grader, and P. Halleck.) 